\title{
HELPING THE TRANSLATOR CHOOSE: THE CONCEPT OF A DICTIONARY OF EQUIVALENTS
}

\author{
WERONIKA SZEMIŃSKA \\ Institute of Specialist and Intercultural Communication, University of Warsaw, Poland \\ SZEMIŃSKA, Weronika: Helping the Translator Choose: The Concept of a Dictionary \\ of Equivalents. Journal of Linguistics, 2017, Vol. 68, No 2, pp. 355 - 363.
}

\begin{abstract}
The purpose of the article is to present the innovative concept of a dictionary of equivalents, a reference work designed specifically for translators of legal texts. The article describes the features of legal terminology which render legal translation particularly difficult, such as polysemy and synonymy as well as incongruence among legal systems. Then it proposes a classification and labelling system of equivalents which ought to be offered in a terminographic reference work for legal translators.

Keywords: dictionary of equivalents, legal language, legal translation, congruence, equivalence
\end{abstract}

\section{INTRODUCTION}

"As translators we all know deep in our hearts that legal translation is impossible. The very expression legal translation seems to be a contradiction in terms (...)." This statement by P. Chaffey [1, p. 69] may sound radical, but also rather insightful. What makes legal texts untranslatable? Unlike other disciplines, law is a national phenomenon. Each national legal system is independent and has its own terminological apparatus, conceptual structure, rules of classification, sources of law, methodological approaches and socioeconomic principles [2, p. 13]. Moreover, since law defines reality, we may venture to say that each society lives in its own legal universe, which develops throughout centuries and reflects a people's history and culture [3, pp. 23-24].

This disconcerting nature of law predictably finds its reflection in the legal language, or rather in legal languages. As a result of the culture-bound nature of law, there is no single universal legal language, with rare exceptions. Only few areas, such as public international law or European law, have an international character and therefore use international legal terminology. Apart from that, some common ground may be found in branches of law such as constitutional, administrative, civil or criminal law $[4$, p. 122].

P. Chaffey's statement quoted at the beginning ends almost resignedly: “(...) and yet we do have to translate legislation and legal documents." If so, how can this impossible task be completed? And how can terminography aid the translator in their job? The aim of the present article is to propose a tool that would greatly facilitate the translation process, and in particular one of its stages, namely the phase of transfer from the source into the target language, when equivalents are chosen. First, the legal lexicon will be characterised, followed by a description of how its features af- 
fect the process of translation. Finally, the concept of the dictionary of equivalents will be presented.

\section{THE LEGAL LEXICON}

The potentially most interesting feature of legal language is the legal lexicon. The vocabulary may be classified according to various criteria, for instance the type of text in which it is used, as proposed by G.-R. de Groot [5, pp. 18-19]. Thus we can divide legal vocabulary into (i) that used in statutes and other regulations (with the subcategory of expressions explicitly defined by the legislator), (ii) that used by lawyers or in commentaries, and (iii) that used in general publications concerning the legal system in question. Another classification, by Gizbert-Studnicki [6, pp. 4445], refers to the layers of legal vocabulary: (i) vocabulary related to the object of regulation, i.e. the area of social practice which a given regulation concerns, (ii) vocabulary related to the method of regulation, i.e. a large set of characteristically legal expressions which recur frequently in a given branch of law, and (iii) vocabulary being a consequence of the normative character of legal texts, i.e. a set of frequently used expressions referring to the notions related to obligations, claims, rights, competences etc., which are common to the entire legal system in question. Similarly, M. Chromá [7, p. 15] lists: (i) 'pure' law terminology, which is a scarce group of expressions that are not used in other contexts, (ii) law terminology found in everyday speech, including expressions with related general and legal meanings, with differing general and legal meanings and with several meanings, and (iii) everyday words assigned a special connotation in a given legal context, i.e. expressions whose meaning is either expanded or narrowed by means of a legal definition.

The fact that everyday words may be assigned a precise and often differing meaning in the legal context evidences the autonomy of the legal language in relation to the general language. It stems from the legislator's right to define the expressions used by means of legal definitions [8, pp. 9-10]. This may lead to certain complications. It happens namely that the legislator is inconsistent in the use of a term or that they use the same expression derived from the general language now in the legal, now in the general sense. Furthermore, one term may carry differing meanings in various branches of a single legal system, as for instance the English term 'charge', which can refer to a formal accusation of a crime in criminal law, to a legal interest securing the payment of money in contract law, and to a financial punishment in administrative law. Another cause of terminological polysemy is the situation when various legal systems are expressed by means of one ethnolect, as in the case of i.a. English, German, or French.

H. E. S. Mattila [9, pp. 109-112] divides polysemy in legal language into two categories: consistent and inconsistent. Consistent polysemy characterises a term that has several closely related meanings, often hierarchical or overlapping. Inconsistent polysemy occurs when the meanings diverge to such an extent that they no longer have anything in common. Finally, legal language often involves synonymy and, in particular, partial synonymy. Often all partial synonyms are used in a text in order to guarantee that the entire semantic field of a concept is covered. 
The differences between law and other specialist disciplines mean that legal translation poses difficulties unknown to translators of other types of texts. The main problems have their source in the nature of law and legal language. Let us say it again: in contrast to many other areas of knowledge and professional activity, law is not an independent being described by humans, but a human construct which is entirely dependent on language. Moreover, it is not a single construct, but exists in as many variants as there are legal systems and ethnolects that express them. Since no single legal reality is given, translation of legal texts entails translating not only between two ethnolects, but also between differing realities - legal systems. It may be depicted in the form of the following figure:

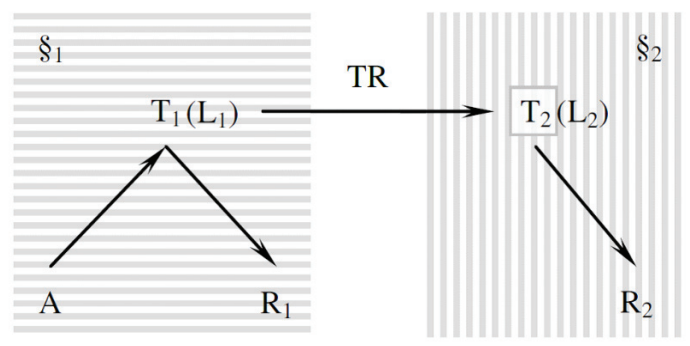

Fig. 1. Model of legal translation

The author $(A)$ produces the source text $\left(T_{1}\right)$ in the source language $\left(\mathrm{L}_{1}\right)$ directed at the primary recipient $\left(\mathrm{R}_{1}\right)$, all of whom function in the primary legal system $\left(\S_{1}\right)$. The translator (TR) produces the target text $\left(\mathrm{T}_{2}\right)$ in the target language $\left(\mathrm{L}_{2}\right)$, the text being directed at the target recipient $\left(\mathrm{R}_{2}\right)$. While the target language and the target recipient are immersed in the secondary legal system $\left(\S_{2}\right)$, the same cannot be said about the target text itself. A translation, albeit expressed in the target language, may have a different legal status in the secondary legal system than the original had in the primary legal system [3, p. 10], [10, pp. 198-199]. This phenomenon is related to the fact that, apart from rare exceptions mentioned previously, the object of the text does not exist in the secondary legal system. A more or less similar object may often be found, yet practically never an identical one. As a consequence, the target language often does not offer any expressions equivalent to the source ones.

This phenomenon is by some scholars [2], [3], [11], [12] referred to as incongruence. Šarčević [2, pp. 232-233] lists six major reasons for this phenomenon in legal terminology: (i) boundaries between the meanings of concepts in different legal systems are incongruent, (ii) the same term designates different concepts in different legal systems expressed by one language, (iii) legal concepts which were transplanted into another legal system have been gradually assimilated and altered their meaning, (iv) a number of terms in each legal system are strictly system-bound and have no comparable counterparts in other systems, (v) indefinite or vague terms are interpreted differently by courts in various jurisdictions, and (vi) some terms with ideological content have different connotations in various cultures. In fact, full congruence between legal terms occurs extremely rarely; de Groot [4, p. 124] even ma- 
intains that it is possible solely in the case of one legal system expressed by two languages. A large number of concepts may be described as convergent, i.e. partly equivalent.

In situations when no congruent or convergent equivalent exists or when it would be unacceptable for other reasons (e.g. as misleading to the recipient), compensation techniques may be applied, examples being: borrowing, possibly accompanied by a literal translation; periphrasis; neologism (based on legal language, other specialist language or general language); neutral (non-technical) term; literal equivalent; or Latin equivalent [4, p. 125], [2, p. 250]. In addition, the choice of translation techniques must be consistent throughout the text and depends not only on the individual translation problem, but predominantly on factors like the purpose of the translation, i.e. its prospective function in the target reality, as well as the knowledge of the recipient, the genre of the text and the relation of the two relevant languages and legal systems. Based on the analysis of these aspects, the translator has to pick the most appropriate translation strategy, which in turn determines the set of techniques which may be applied to handle individual translation problems.

Principally we may speak of two translation strategies: (i) source language and primary legal system-oriented strategy and (ii) target language and secondary legal system-oriented strategy [13, p. 145], which are parallel to the literary translation concepts of foreignisation and domestication. The $\mathrm{L}_{1}$ and $\S_{1}$-oriented strategy involves emphasising the differences between the legal systems by means of using expressions and structures strange to $\mathrm{L}_{2}$ and $\S_{2}$. The $\mathrm{L}_{2}$ and $\S_{2}$-oriented strategy, on the other hand, aims to blur said differences [14, p. 36]. A simple example illustrating both types of equivalence is the translation of the Polish expression 'akt oskarżenia' into American English. The American law knows a similar concept expressed by the term 'indictment.' Thus the original term could be translated as 'indictment' if we want to stress the similarities between the Polish and the American law, and for instance as 'act of indictment' if we want to stress the disparities. In the latter case, the American term is modified by introducing a foreign element which refers to the Polish legal system. The equivalent is still comprehensible to an American reader. A more literal translation of the term ('act of accusation') would go even further to foreignise the text.

As may be inferred from the above considerations, choosing a right equivalent in legal translation is a most arduous task. It requires analysing the original concept, studying the secondary legal system in search for similar concepts, and if any are found, comparing them to the source concept to determine the degree of equivalence/congruence, deciding whether they are acceptable translations, and if not, applying a fitting compensation technique. This in turn involves researching other legal systems expressed by the same language, if any exist, including Roman law, inspecting the potential connotations of a literal equivalent or an equivalent based on another specialist language or on the general language, and the list goes on. Plus, the final choice must be consistent with the translation strategy assumed. Completing this complex task requires much more than a perfect command of the source and the target language, namely deep legal expertise and ability to perform comparative legal analysis. Indeed few translators have all those competences and sufficient time 
while working on a translation. That is why they (rather logically) expect help from legal dictionaries. These are, however, often no more than word lists offering unsubstantiated translations without indications of differences in meaning between the source and the target language [15, p. 2], [16]. Labelling systems used in some dictionaries usually indicate the branch of law or the legal system from which a given equivalent stems, but no more than that. If any neologisms are offered, they are not marked as such. Similarly, there are no indications of translation strategies which a particular solution follows, i.e. whether it is a $\S_{1}$ or $\S_{2}$-oriented equivalent. Finally, the overall number of equivalents is often insufficient.

\section{DICTIONARY OF EQUIVALENTS}

The above considerations seem to suggest that the answer to the translator's problem is, firstly, to provide a maximum number of possible equivalents of various types, secondly, to indicate the differences between them, and thirdly, to explain any incongruencies between equivalents stemming from the secondary legal system or another legal system expressed by the same ethnolect and the original term. Only then will the translator be able to make a well-informed choice of the most fitting equivalent in the given context.

Designing a dictionary that would aid the translator in choosing the best equivalent should therefore commence with preparing a classification of equivalents. First and foremost, they may be divided into two categories: actual equivalents and neologisms. Actual equivalents are terms that refer to concepts existing in the secondary legal system. Neologisms, on the other hand, are not necessarily recent or isolated expressions outside mainstream language, but any expressions which do not refer to concepts in the secondary legal system. Thus, both an expression from another legal system expressed by the same ethnolect as $\S_{1}$ and a literal translation of the original term may be seen as neologisms.

Actual equivalents may be further divided into congruent and convergent ones. The former are expressions representing $\S_{2}$ concepts that share most vital characteristics with the $\S_{1}$ concept in question (as has been said above, full congruence is virtually impossible). The latter in turn represent $\S_{2}$ concepts which only partially correspond to the original concept. Each of these two types may be further subdivided into valid and outdated equivalents. While valid equivalents reflect concepts that are still in use under effective law, outdated equivalents represent notions that have become obsolete, but are still recognisable by target language recipients (an example could be the obsolete English term 'custody' referring to the rights and responsibilities of parents with respect to their child).

Neologisms in turn may be classified according to the translation technique applied or to the strategy they follow. From the point of view of translation techniques, we can discern neologisms stemming from other legal systems than $\S_{2}$ (which again may be congruent or convergent, valid or outdated), including borrowings, neologis$\mathrm{ms}$ from the language for general purposes, neologisms from another language for specialist purposes, literal translations, periphrases and institutional neologisms (i.e. expressions used by a particular institution, such as a state agency or a company). 
The aspect of translation strategy allows us to differentiate between $\S_{1}$-oriented and $\S_{2}$-oriented neologisms.

The above classification may be presented in the form of the below figure, including the proposed labels for each class (the sign ' $x$ ' in the label for terms from other legal systems stands for an abbreviation of the name of the country whose legal system is involved, so in its final version the label could look like this: $\mathrm{N}_{\S \cup S \equiv}$, if the legal system in question were American law):

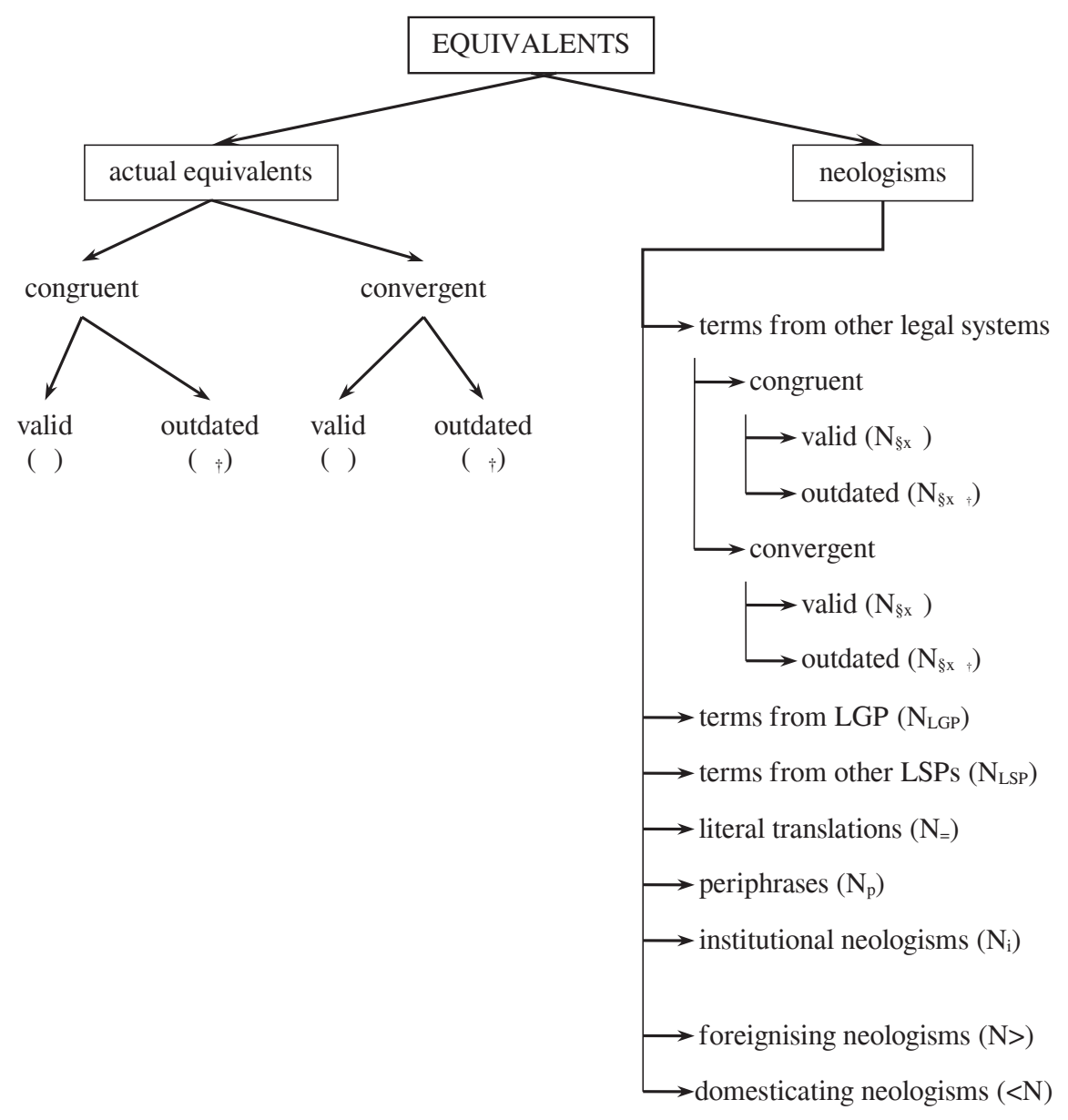

Fig. 2. Classification of equivalents and their labels

If an expression has several synonymous equivalents within the same class, two further labels may be introduced which will allow the translator to choose the right one: frequency and presence in normative acts. The fact that some expressions are used more often than others hardly requires an explanation. The second marker is based on the fact that some legal terms do appear in prescriptive texts, such as statutes, while others are used only in secondary legal texts, for instance commentaries or 
academic publications. An example could be the German terms for adoption: 'Adoption' and 'Annahme als Kind,' with the former being much more frequently used, but not present in the German Civil Code, which uses the latter expression. The proposed labels could be uppercase ' $§$ ' for the prescribed term and likewise uppercase numerals ' 1 ,' ' 2 ' etc. to indicate frequency.

Sample entries in a dictionary of equivalents could look as shown below:

$$
\begin{aligned}
& \text { przysposobienie } \\
& \equiv \text { Annahme als Kind }^{\S, 2} \text {, Adoption }
\end{aligned}
$$

Fig. 3. Sample entry from a German-Polish dictionary of equivalents

Here the Polish term 'przysposobienie' ('adoption') has two actual congruent equivalents in the German legal system. They differ in terms of frequency and legal status: while 'Annahme als Kind' is the actual legal term used in the civil code, it is used less frequently than the common 'Adoption'.

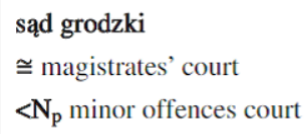

Fig. 4. Sample entry from an English-Polish dictionary of equivalents

In this case the dictionary offers two ways of translating the Polish term 'sąd grodzki': by means of either the convergent (that is only partially similar) term from the legal system of England and Wales, namely 'magistrates' court', or the primary legal system-oriented neologism 'minor offences court'. The latter expression does not refer to any institution in the secondary legal system, but merely succinctly explains the function of the Polish institution; hence it is marked as a periphrasis.

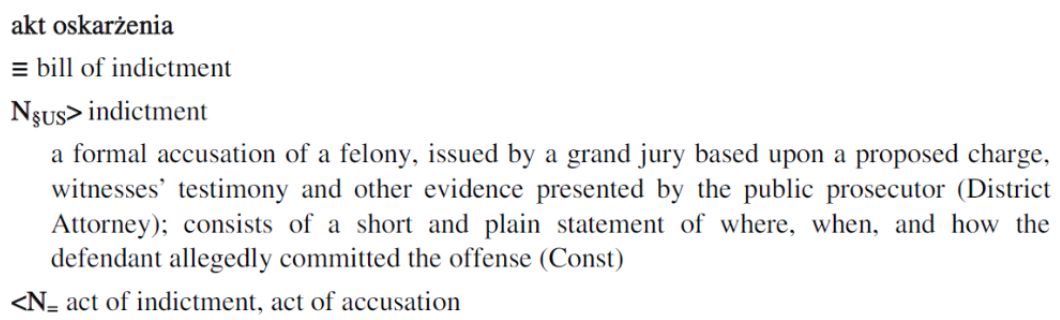

Fig. 5. Sample entry from a Polish-English dictionary of equivalents

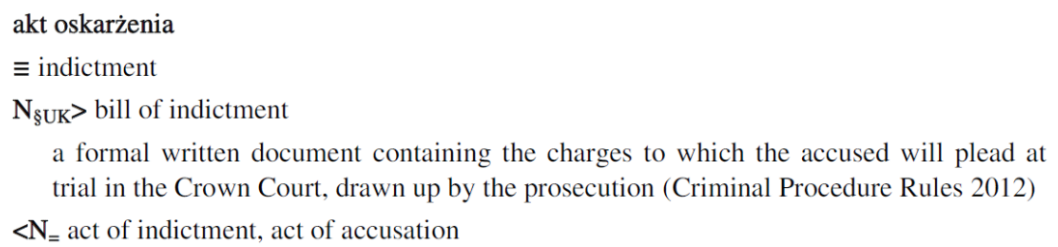

Fig. 6. Sample entry from a Polish-American dictionary of equivalents 
The last two examples show why it is crucial to make separate dictionaries for each pair of particular legal systems and not languages. In a Polish-English dictionary (Fig. 5), that is one facilitating translation between the legal systems of Poland on the one hand and England and Wales on the other hand, the actual congruent equivalent of the term 'act oskarżenia' is 'bill of indictment'. However, the translator may want to emphasise that the two institutions are in fact not identical and rather use a term that will be less familiar to the final recipient. They may thus want to use a neologism in the form of a literal translation, namely 'act of indictment' or, even more exotically, 'act of accusation'. Another possibility is to use a neologism which stems from the American legal system (i.e. it is a neologism from the perspective of the law of England and Wales, not of the global English legal language in general), namely 'indictment'.

Figure 6 presents a reverse case: in a Polish-American dictionary the term 'indictment' will be the actual congruent equivalent, while the British term 'bill of indictment' will serve as a neologism. In each case the literal translation is marked as a source legal system-oriented neologism, while the terms from the respective foreign legal systems count as target legal system-oriented ones (being relatively familiar to the final recipients).

What might strike a careful reader is the lack of any definitions of actual equivalents (or the source terms, for that matter), while neologisms from other legal systems are followed by explanations and indications of the source of regulation. Worse still, the entries contain no grammatical or lexical information whatsoever. This stems from the fact that the dictionary of equivalents was designed not as an isolated reference work, but as an element of a system of dictionaries for translators of legal texts, comprising also an explicative dictionary, a contrastive dictionary, a combinatorial dictionary and a concise translation dictionary. The explicative dictionary handles issues encountered by translators in the first stage of their work, i.e. it aids them in understanding the source text by providing definitions of the source terms. The contrastive dictionary facilitates the comparison of the two legal systems involved by listing all actual equivalents and offering their definitions. The combinatorial dictionary is used in the final stage of translation, i.e. in the production of the target text, when the translator needs grammatical and lexical information concerning the use of the elected equivalent. The concise dictionary contains the most essential elements from all other volumes.

Full information the translator may need can be obtained through the study of all volumes. The idea to split information among four dictionaries is based on the finding, presented i.a. by S. Tarp [17, p. 37], that problems in translation do not necessarily occur at all the stages of the translation process: they can appear at one of them, at two, or at all. Depending on the problem complex, various dictionaries can be handy: a monolingual source language dictionary, a monolingual target language dictionary, or a bilingual dictionary. Sometimes the translator needs predominantly definitions, and at other times rather collocations. Thus, each element of the system of dictionaries can stand on its own, aiding the translator in solving problems related to a particular stage of the translation process. The dictionary of equivalents is assigned to the stage of transfer and therefore contains only information necessary to choose a proper equivalent. 


\section{CONCLUSION}

The dictionary of equivalents is a concept of a new tool for legal translators. It is supposed to cater to their needs in respect of choosing a proper equivalent: it offers an extensive list of equivalents with relevant labels indicating their status, background and implications. The dictionary works best as an element of a system of dictionaries, which comprises reference works that are assigned to the remaining stages of the translation process and handle other aspects of legal terminology. However, the classification of equivalents and the system of their labelling may be applied in any dictionary designed for translators. Such a lexicon would go some of the way towards aiding the translators in achieving the impossible.

\section{References}

[1] Chaffey, P. N. (1997). Language, Law and Reality. In On the Practice of Legal and Specialised Translation: Papers from the Third International Forum of Legal and Specialised Translation held in Cracow on 7th and 8th September, 1996, pages 69-84, The Polish Society of Economic, Legal, and Court Translators TEPIS, Warsaw, Poland.

[2] Šarčević, S. (1997). New Approach to Legal Translation. Kluwer Law International, The Hague London - Boston.

[3] Cao, D. (2007). Translating Law. Multilingual Matters Ltd., Clevendon - Buffalo - Toronto.

[4] De Groot, G.-R. (1990). Die relative Äquivalenz juristischer Begriffe und deren Folge für mehrsprachige juristische Wörterbücher. In Translation and Meaning, Part 1. Proceedings of the Maastricht Session of the 1990 Maastricht-Łódz Duo Colloquium on 'Translation and Meaning', Held in Maastricht, The Netherlands, 4-6 January 1990, pages 122-28, Euroterm, Maastricht, Netherlands.

[5] De Groot, G.-R. (1999). Guidelines for Choosing Neologisms. In Aspects of Legal Language and Legal Translation, pages 17-21, Łódź University Press, Łódź, Poland.

[6] Gizbert-Studnicki, T. (2004). Sytuacyjne uwarunkowanie językowych właściwości tekstów prawnych. In Język - prawo - społeczeństwo, pages 37-48, Uniwersytet Opolski, Opole, Poland.

[7] Chromá, M. (2004). Legal Translation and the Dictionary. Max Niemeyer Verlag, Tübingen.

[8] Roszkowski, S. (1999). The Language of the Law as Sublanguage. In Aspects of Legal Language and Legal Translation, pages 7-16, Łódź University Press, Łódź, Poland.

[9] Mattila, H. E. S. (2006). Comparative Legal Linguistics. Ashgate, Aldershot.

[10] Tognini-Bonelli, E. (1996). Towards Translation Equivalence from a Corpus Linguistics Perspective. International Journal of Lexicography, 9(3):197-217.

[11] Hausmann, F. J. (1977). Einführung in die Benutzung der neufranzösischen Wörterbücher. Max Niemeyer Verlag, Tübingen.

[12] Kubacki, A. D. (2002). Problemy konfrontacji polsko-niemieckiej terminologii podatkowej. In Z problematyki języków specjalistycznych: materiały z konferencji, pages 63-72, WSZMiJO, Katowice, Poland.

[13] Roelcke, T. (2005). Fachsprachen. Erich Schmidt Verlag, Berlin.

[14] Kielar, B. Z. (1977). Language of the Law in the Aspect of Translation. Wydawnictwa Uniwersytetu Warszawskiego, Warszawa.

[15] De Groot, G.-R. and van Laer, C. J. P. (2005). Bilingual and multilingual legal dictionaries in the European Union. A critical bibliography. Accessible at: http: / / arno. unimaas. nl / show . cgi ? fid $=3130$.

[16] De Groot, G.-R. and van Laer, C. J. P. (2006). The Dubious Quality of Legal Dictionaries. International Journal of Legal Information, 34(1):65-86.

[17] Tarp, S. (2005). The concept of a bilingual dictionary. In Schreiben, Verstehen, Übersetzen, Lernen. Zu ein- und zweisprachigen Wörterbüchern mit Deutsch, pages 27-41, Peter Lang, Frankfurt am Main - Berlin - Bern - Bruxelles - New York - Oxford - Wien. 